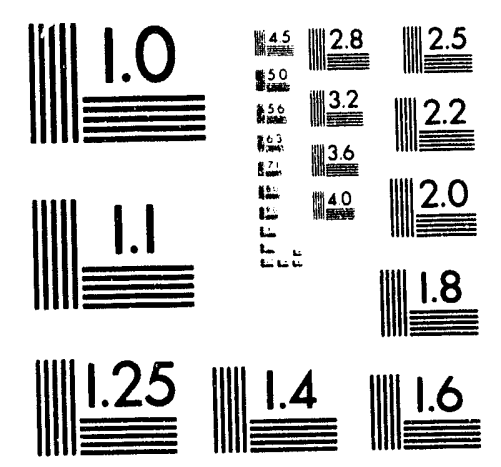



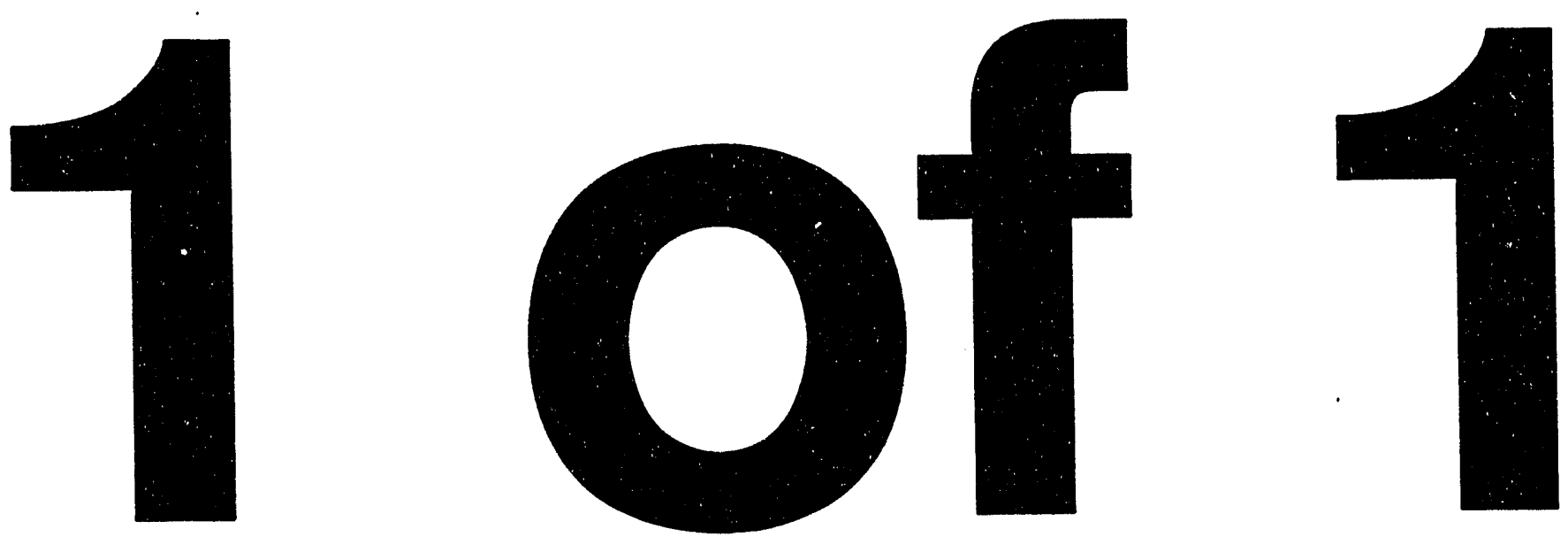


\title{
Evaluation of a Radiation Worker Safety Training Program at a Nuclear Facility
}

\author{
J. E. Lindsey \\ Date Published \\ May 1993
}

\section{(2) Westinghouse \\ Hanford Company Richland, Washington}

Hanford Operations and Engineering Contractor for the

U.S. Department of Energy under Contract DE-AC06-87RL10930

Copyright License By acceptance of this article, the publisher and/or recprent acknowledges the U.S. Government's right to retain a nonexclusive, royalty-treo license in and to any copyright covering this pezer

This document was prepared in partial fulfillment of the requirements for a Master of Science degree in Organization Development from Central Washington University, Ellensburg, Washington. 


\section{LEGAL DISCLAIMER}

This report was prepared as an account of work sponsored by an agency of the United States Government. Neither the United States Government nor any agency thereof, nor any of their employees, nor any of their contractors, subcontractors or their employees, makes any warranty, express or implied, or assumes any legal liability or responsibility for the accuracy, completeness, or any third party's use or the results of such use of any information, apparatus, product, or process disclosed, or represents that its use would not intringe privately owned rights. Reference herein to any specific commercial product, process, or service by trade name. trademark, manufacturer, or otherwise, does not necessarily constitute or imply its endorsement, recommendation, or favoring by the United States Government or any agency thereof or its contractors or subcontractors. The views and opinions of authors expressed herein do not necessarily state or reflect those of the United States Government or any agency thereof.

This report has been reproduced from the best available copy. Available in paper copy and microfiche.

Available to the U.S. Department of Energy and its contractors from

Office of Scientific and Technical Information

P.O. Box 62

Oak Ridge, TN 3783

(615) 576.8401

Available to the public from the U.S. Department of Commerce National Technical Information Service

5285 Port Royal Road

Springtield, VA 22161

(703) $487-4650$

Prinled in the United Stalos of America

DISCLM-1.CHP (1.91) 
WHC-MR-0383

Document Title:

Prepared by:

Approved by:
Evaluation of a Radiation Worker

Safety Training Program at a Nuclear Facility

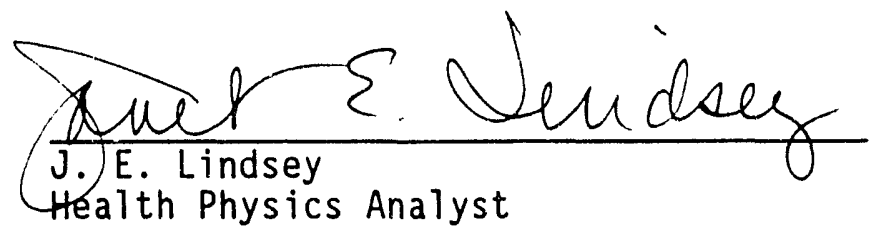

J.A. Ard, Manager

Health Physics Administration
SEP $10 \%$

$0 S T 1$

$\frac{6-30-73}{\text { Date }}$ 


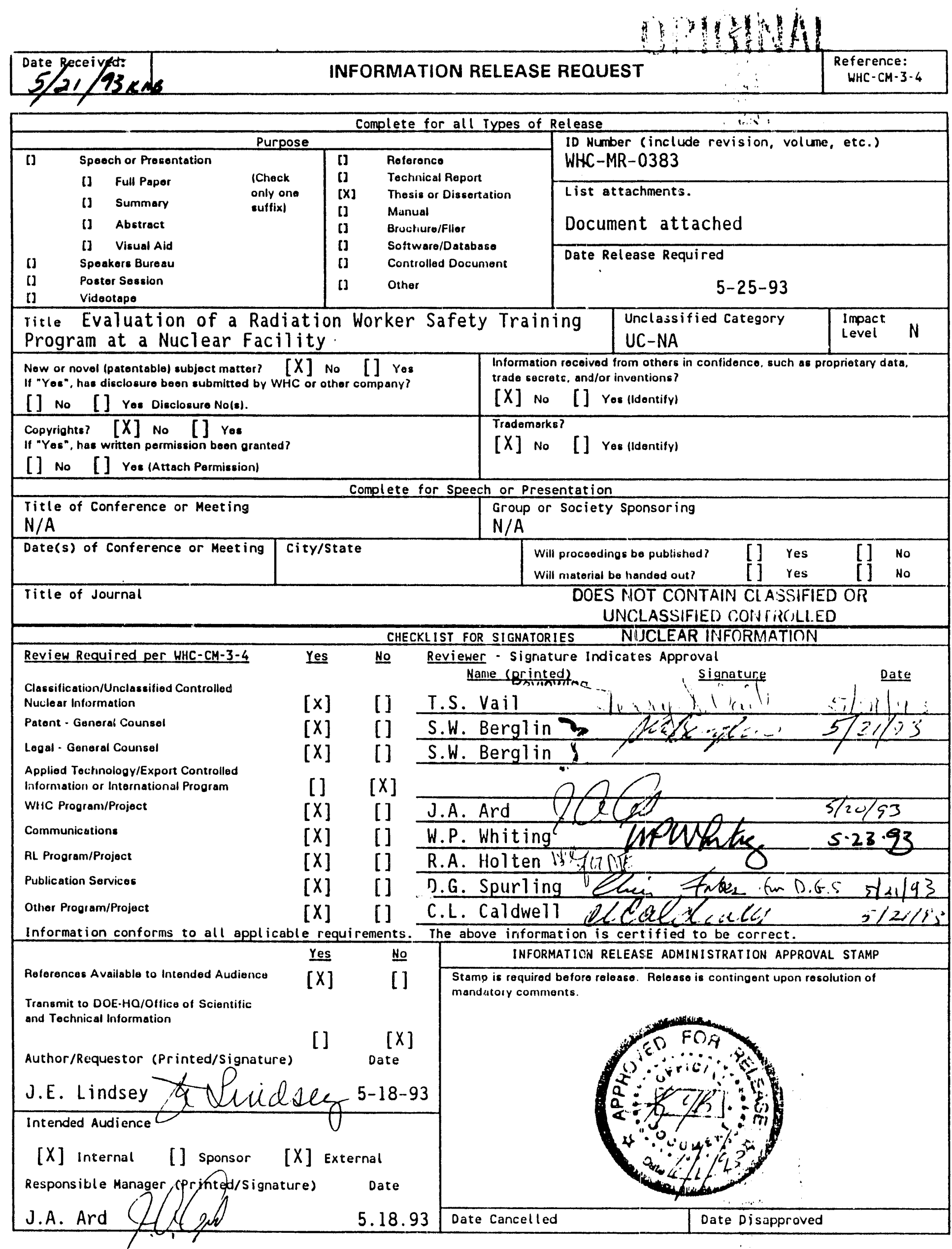

BD-7600-062 (08\}91) WEF074 
WHC-MR-0383

EVALUATION OF A RADIATION WORKER

SAFETY TRAINING PROGRAM AT A NUCLEAR FACILITY

by

Janet E. Lindsey

May, 1993

A radiation safety course was evaluated using the Kirkpatrick (1976) criteria of training evaluation as a guide. Thirty-nine employees were given the two-day training course and were compared with 15 employees in a control group who did not receive the training. Cognitive results show an immediate gain in knowledge, and substantial retention at 6 months. Implications of the results are discussed in terms of applications to current radiation safety training as well as follow-on training research and development requirements. 
WHC-MR-0383

\section{ACKNOWLEDGEMENTS}

I would like to thank the personnel in the technical training group for their support and assistance in this project. 
WHC-MR-0383

\section{CONTENTS}

Page

List of Tables................................

\section{CHAPTER}

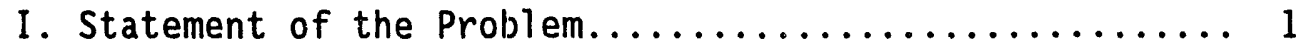

Evaluation of Safety Training Programs.......... 1

Nuclear Safety Training Programs.............. 2

II. Literature Review........................ 4

Safety Training Evaluation Practices........... 5

Training Effectiveness Criteria............. 7

Radiation Worker Safety Training............ 8

Purpose of This Research................. 10

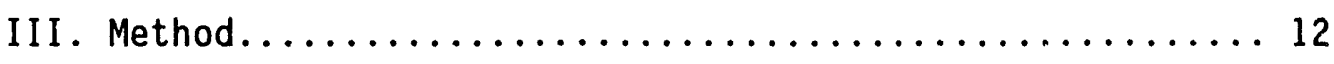

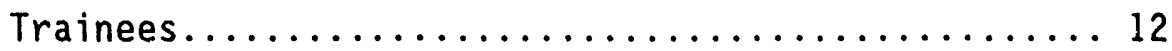

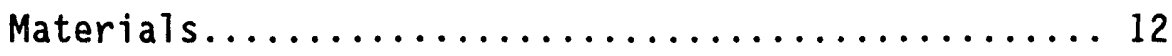

Procedure............................ 13

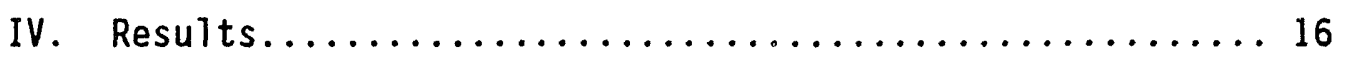

Trainee Reaction Data.................... 16

Cognitive Test Data.................... 18

On-the-Job Self-Report Data................... 23

Development of On-the-Job Measures..............25 
CONTENTS Continued

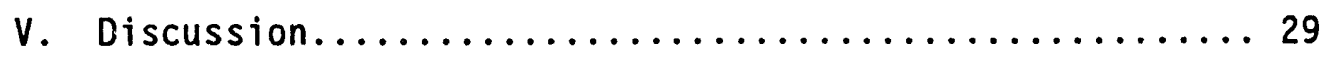

Evaluation Approach.......................... 29

Conclusions and Recommendations................... 31

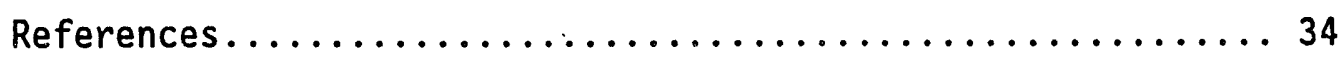

Appendixes

A. Course Evaluation Sheet Safety Training....... 36

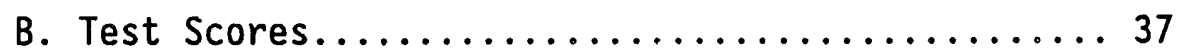

C. Post Training Evaluation Safety Training....... 39

D. Radiation Worker Safety Training Evaluation Questionnaire..................... 41

E. Number of Misses per Question on Test........47 
WHC-MR-0383

\section{LIST OF TABLES}

TABLE

Page

1. Non-Equivalent Control Group Design............ 14

2. Responses from Trainee Questionnaire,

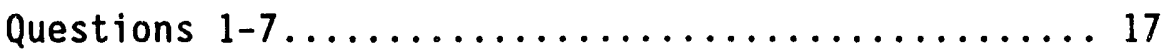

3. Comments from Trainee Evaluation Sheets, July-August, $1992 \ldots \ldots \ldots \ldots \ldots \ldots \ldots \ldots \ldots \ldots \ldots$

4. Means and Standard Deviations Across Groups........ 21

5. Mean Test Scores in Graph Form.............. 22

6. Comparison of Cognitive Test Scores............ 24

7. Behavioral Dimensions Resulting from the Critical

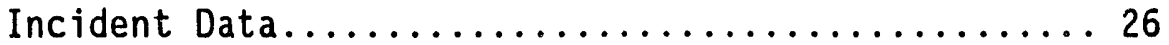

8. Test Areas Most Frequently Missed............. 28 


\section{CHAPTER I}

Statement of the Problem

The Radiation Worker Training course is required by a 11 personnel who will need access to radiological areas on a regular basis. This training program was recently changed from an 8-hour course to a 16-hour course. In June of 1992, this course was again changed. In response to dictates from a federal agency, a technical training group developed a more comprehensive 16-hour class, and a less comprehensive 8-hour class. The 8-hour class was developed to train those personnel who require only occasional access to radiation areas, and was taught during June 1992, as a pilot for possible future use. The 16-hour class has continued as directed. Should this course material and presentation prove effective, it is scheduled to be adopted throughout a federal agency as a standard format The purpose of this study was to evaluate the effectiveness of this revised training program.

\section{Evaluation of Safety Training Programs}

An evaluation of a training program should determine the utility, necessity, and effectiveness of the program (Wexley and Latham 1991). Safety training, in particular, is an area in which the effectiveness must be high to promote worker safety and the associated benefits for the corporation or organization. Failure to understand the safety measures in effect in any organization can be harmful and costly, if not fatal. In 1970, the Occupational Health and Safety Administration (OSHA) was established as a federal agency to monitor the safety and health of the American worker throughout the nation. Industrial safety standards must be met or OSHA may cite or fine the organization, or may institute court proceedings to enforce regulations (Wexley and Latham 1991). While OSHA does not certify or approve 
training programs, it does require that training be conducted and that proof of the training be available to an inspection team. Employers must provide for the safety of their employees by providing adequate training, and it has beell shown that there is generally a direct relationship between training and enhanced performance (Feiza and Klemm 1989).

\section{Nuclear Safety Training Programs}

In the nuclear industry, the ramifications to the general public are incorporated into the overall need to maintain safe working conditions and methods for the radiation workers, because an error at a nuclear facility can prove fatal not only to the workers involved but to the neighboring public. The Nuclear Regulatory Commission (NRC) regulates the milling and processing of nuclear materials for radiation safety purposes throughout the United States. Some individual states provide the same or additional regulations. The NRC requires that all personnel, who work in or frequent areas that have radioactive materials present, must receive radiation safety training.

While the NRC can provide general information pertaining to radiation safety training, each employer is required to develop and maintain adequate training programs for their employees and to maintain auditable records of that training (McElroy and Brodsky 1986). Nuclear facilities throughout the United States must comply with this requirement by developing various safety training programs for radiation workers. Some of the initial programs primarily are offered as initial information for the workers (McElroy and Brodsky 1986). Additionally, the majority of tr.e safety programs provide actual hands-on-training and academic training for the workers to enhance 
safety for those at the nuclear facility and their neighbors. The hands-ontraining, or practical training, involves actual use of various items, such as gloveboxes, survey instruments, and practice in dressing and undressing in protective clothing.

The NRC requires basic academic training in four major areas:

"(a) principles and practices of radiological health and safety;

(b) radioactivity measurements, standardization and monitoring

techniques, and instruments; (c) radiation calculations; and

(d) biological effects." (Shapiro 1990, p. 269)

These four areas are mandatory for those workers who will be working directly with radionuclides, or who will be monitoring those who do so. Each nuclear facility must provicie training in these areas, and the courses taught are based on the principles outlined above.

The training program that was evaluated in this study is a required course for al? radiation workers on the Hanford Site, and must fulfill the requirements as stated above. Safety in radiation work is a primary goal for the Hanford Site, and this course has been refined to provide the necessary requirements for academic and hands-on-training. This study was conducted to evaluate the effectiveness of a new format and to provide feedback information to a technical training group for further improvements in the radiological safety training program on the nuclear site. 
WHC-MR-0383

\section{CHAPTER II}

Literature Review

Safety and productivity are connected facets of job performance at a nuclear facility because of the possible effects of unsafe behavior on the workers as well as the general public. Personnel, once trained, may perform their jobs well even in a less than supportive atmosphere. However, safety is another issue. While safety measures are dictated by federal regulations, the degree to which each nuclear facility accomplishes those measures may be directly related to employee involvement in the safety system (Lawler 1985). Management must not only be supportive, but must continually involve the employees actively in the safety programs at the facility. This supportive involvement not only increases the impact of the education on the workers, but increases the effectiveness of the organization in promoting safety.

Management must react to the educational level of its employees by supporting their need for involvement (Lawler 1985). Employees are on the line when it comes to safe practices, and their total involvement in the program is a necessity. Management reinforcement for safe practices is not only a requirement for nuclear safety, but a highly supportive mechanism for worker involvement and cooperation.

Much of our behavior is learned through modeling, and people behave safely at a level that is consistent with their training and capabilities (Bandura 1977). People reason and make decisions based on knowledge structures which they extrapolate from ordinary life experiences and various generalized, context-sensitive rules, such as "permission," "obligation," and "causation" (Cheng and Holyoak 1985). Training methods establish these context-sensitive rules that we learn; parents, teachers, and trainers teach 
us what "permission" means. Training reinforces the concept of "obligation" and teaches us that certain behaviors, such as coloring on a wall, "cause" certain results, such as being sent to one"s room. Rules and required behavior changes that accompany them are incorporated into training from early childhood.

\section{Safety Training Evaluation Practices}

The skills and knowledge required to promote safety can be learned through training. Proficiency on the job should be evaluated using transfer of training principles, and should be evaluated closely, because even small differences in the application of safety measures can have enormous consequences within the bounds of the nuclear industry (Giewitz, Spiker, and Harris 1988). Consequently, evaluation of training effectiveness must be tracked into the posttraining environments to examine the utility of the training to on-the-job activities.

Attitudes about training, as related on post-training evaluations by the trainees, may not always be indicators of the true effectiveness of the training as it applies to on the job perfornance (Tannenbaum, Mathieu, Salas, and Cannon-Bowers 1991). Common nuclear industry practice is to evaluate training by means of trainee evaluation forms that are filled out by the trainees at the end of the training session (Vinther 1991). While attitudes toward training are potentially valuable input to the instructors about the class, its presentation and the materials and information imparted, it does not necessarily apply directly to actual work performance. Results from training evaluation procedures are limited in scope. The trainees are reacting to the session itself and to the qualities of the trainer, while the eventual results of actual job application are not being tallied 
(Vinther 1991). Therefore, the true value of the course is not actually validated by the immediate reaction of the trainees (Sanders 1989).

A more useful measure of training effectiveness is the extent to which the pre-specified goals match the training outcomes (Nowakowski 1989). If such goals do match the outcomes (increased safety on the job), then the training is determined to be effective. An evaluation of the effectiveness of training can examine the proficiency and effectiveness with which the trainees perform their functions.

Training evaluation procedures should also examine the economic and psychological effects of the training. Costs should be reduced or at least maintained, and the benefits should be increased (Swanson 1989). In the context of safety training, safety on the job should increase or maintain an expected, required level. If safety is maintained or increased, the costs for repair or replacement of materials should decrease and the cost in human injury or loss of life should decrease. Therefore, the benefit to the company is increased productivity and job performance because of lack of down time caused by injury or parts and material replacement, and the associated costs of fines or lawsuits should decrease (Peter 1990).

The determination of radiation worker safety training effectiveness can also be extended to an analysis of future course development by evaluating a possible shift from strictly program-driven training based on federal regulatory requirements, to a needs-driven, performance based-training program. This proactive approach looks critically at future as well as present goals. The extent to which changes or improvements can upgrade the training to make it truly job effective (Brinkerhoff 1989) should be evaluated. 
The redirection of training evaluation to an analysis of future needs is not a new focus on the subject (Brandenburg 1989). This focus is, however, a direction that must be attended to very closely in the nuclear industry, especially in the area of safety training. Additionally, the evaluation can be a useful tool in building management commitment to training. Training effectiveness is directly related to the level at which job performance is established, measured and managed, both by management and the individual workers, (Lawler 1985; Russe11, Terborg, and Powers 1985). If workers know that managers have a commitment not only to the training, but to the followup and support of the individual workers, the workers will be more highly motivated to take "ownership" of the job (Gill 1989). In this case, the ownership implies direct responsibility for the safety of each individual on the job.

\section{Training Effectiveness Criteria}

Various criteria are used to measure the effectiveness of training programs. The following criteria were proposed by Kirkpatrick (1976) and discussed by Wexley and Latham (1991):

1. Reaction criteria measure trainee attitudes toward the program--its content, the trainer, the tools and methods and whether the course seemed applicable to them. This is usually done by means of a trainee evaluation form immediately after the course is over.

2. Learning criteria assess the knowledge and skills of the trainees-usually by testing at the end of the course. Normally, this is a paper and pen test, although some courses require the trainees to show some proficiency in a physical activity associated with the job. In the case of the Radiation Worker Training class, the trainees are also expected to demonstrate the methods of dressing and undressing in radiation worker protective clothing, in 
addition to demonstrating other "hands-on" capabilities. However, this part of the course is not tested by other than direct observation of the course instructor within the immediate context of the class.

3. On-the-job behavior criteria measure the trainee's transfer of behavior learned in the classroom to the job environment. Retesting, questionnaires, and interviews with trainees, supervisors, and peers are methods for ascertaining such transfer of training to the job.

4. Results criteria consist of outcomes such as reduced turnover, absenteeism, and accidents. Cost benefits can be determined by converting the actual productivity increases into dollar savings (Wexley and Latham 1991).

Reaction and learning criteria are immediate measurements of the training program itself and are "internal" measures of the effectiveness of the training obtained in the classroom environment. The behavior on the job and the results are external measures of the training program. The success of the program as shown by the external factors must be weighed against other factors that are not related to the training itself, such as pay increases, and environmental and management changes. They do show, however, that training does have an effect on job behavior and can produce effective results. Radiation Worker Safety Training

The Radiation Worker Safety Training course is mandatory for all personnel who will be working at the nuclear facility in areas that have radiation materials, or for those workers who may need more than an occasional access to those facilities, and complies with federal regulations. To gain access, the workers are required to take the course and pass the test with a minimum score of $80 \%$ by answering 40 out of 50 questions correctly. This is an initial course given to instruct radiation workers in the fundamentals of 
radiation protection. The course content includes training about the acute and chronic effects of exposure to radiation, and the risks associated with that exposure.

Training is also given on the various modes of occupational radiation exposure and the methods used for protection, monitoring, and contamination control. Personnel decontamination is discussed and attention is stressed on the responsibility of the individual to obey the warning signs, alarms and signals. This course was given as an 8-hour session until December 1991. At that time, the session was expanded to a 16-hour class. Currently, the program has been revised again, and is now given as an even more comprehensive 16-hour class. This change began in June of 1992. An 8-hour class was also piloted, which was aimed at those personnel who require only occasional access to radiation areas. The 8 -hour course will be evaluated at a 1 ater date for future use based on need and cost-effectiveness, and is not included in this study.

The technical training group changed the format of the Radiation Worker Safety Training course from a highly intensive 8-hour class to a more relaxed and expanded 16-hour class in December of 1991. It was thought that the extended class would be more beneficial to both workers and to the organization, because it was believed that the 16-hour class would be more "educational" for the workers, and that they would learn more and therefore become more safety conscious. A casual evaluation by the Technical Training group seemed to bear out their feelings that the course had become more effective. The current class was upgraded because of increased federal requirements, and is the subject of this study. The pilot studies began the first week of June 1992. 
There are many benefits to be gained by studying the effectiveness of the Safety Training Program. The primary benefit is that an objective evaluation of the Safety Training program should enhance its effectiveness in long-term knowledge imparted to the personnel on the site, and the benefits of well-educated, knowledgeable personnel are invaluable not only to the personnel themselves, but to the company (Gordon 1991). The cost-benefits of training not only can be seen in dollars, but in intrinsic benefits to the employees and the return benefit to the company of a higher measure of safety. The company must not only encourage and support education and training for its employees, but the company must continue that support once the employees have been trained, thus encouraging and supporting the use of that training. Purpose of this Research

The research was to evaluate the effectiveness of the Radiation Worker Training course at the nuclear facility. Additionally, the research was to provide a model for future evaluations. Using two of the Kirkpatrick criteria of training program effectiveness, learning and reaction, a method was devised to evaluate the Radiation Worker Training course. The trainees were evaluated using the following measures: (1) the trainees were asked their reaction to the class; (2) trainee learning was evaluated by means of a pre-test given before the class, a post-test given at the end of the class, and a delayed post-test given 6 months after the course work was completed; (3) verbal self reports by the trainees of their behavior on the job were used to determine the extent to which the course material was applied after the course; and (4) development of on-the-job behavioral measures were established by evaluating specific outcomes that were expected after the personnel had been trained. For this purpose, a critical incident questionnaire was mailed to a 
group of subject matter experts, and the tallied results were compared to the results of the test questions and the results of the survey questionnaire given at the time of the delayed post-test. The control group was evaluated using only the pre-test followed by the post-test with no training intervention. No reaction or follow-up measures were obtained for the control group. 
WHC-MR-0383

CHAPTER III

Method

\section{Trainees}

The subjects of the study consisted of those personnel trained in the Radiation Worker Training class during the months of July 1992 and August 1992. The personnel who participated in the study were men and women employed at the nuclear facility. Their job categories ranged from entry level to senior staff, and their backgrounds, experience, and education were of a wide range. Their ages ranged from early $20^{\prime}$ 's to late 50 's. There were 38 men and 16 women who took the tests. Experience ranged from several months on the job to many years on the job, either at the nuclear facility or at other federal facilities or at commercial nuclear facilities. The control group was composed of 7 men and 8 women who either were already scheduled to take the training course or were considering taking the course to increase knowledge of radiation areas for job needs. Their gender, ages, and experience were comparable to the training group. Job categories of both groups ranged from entry level to senior staff.

\section{Materials}

The test taken by the trainees and control group was developed in response to requirements by a federal agency. Test scores were obtained by the trainers, and the scored answer sheets provided to the researcher.

Appendix A contains a copy of the trainee evaluation sheet that the trainees filled out subsequent to the training. Appendix $B$ contains the total scores for all the tests, listed according to training and control groups. Appendix $C$ provides a copy of the survey questionnaire given to the trainees at the time of the delayed retest, which contains primarily demographic data 
on times entered radiation areas and general course utility as evaluated by the trainees. Appendix D contains a copy of the critical incident questionnaire used to gather behavioral data on radiation workers. Appendix $E$ provides the list of question numbers and the number missed at each test.

\section{Procedure}

Three separate classes were studied, which included 39 employees. The trainees were radiation workers with varying degrees of background in the nuclear industry, but all were required to certify by passing this course in order to enter radiation areas to work or to work in proximity to radiation areas.

The control group of 15 employees received the pre-test and the post-test at the same time as the training group. None of this study personnel had taken the course. The non-equivalent control group experimental design (Saal and Knight 1988) used is listed in Table 1.

All of the subjects participated voluntarily in the study, signing an agreement io participate which also explained the confidentiality of the results to them. The pre-tests were administered on one day, and the posttest was administered the following day. At this time, a trainee evaluation form (see Appendix A) was provided to the trainees, and 28 responded.

A delayed retest was administered 6 months later to those of the training group who agreed to return for the testing, using the same test. Approximately 10 of the training group employees were no longer on the site, and were therefore not available for the retest, and of the 29 remaining at the site, only 10 of the trainees volunteered to return for the test. The compiled test scores are listed, by subject, in Appendix B. 
Table 1.

Non-Equivalent Control Group Design

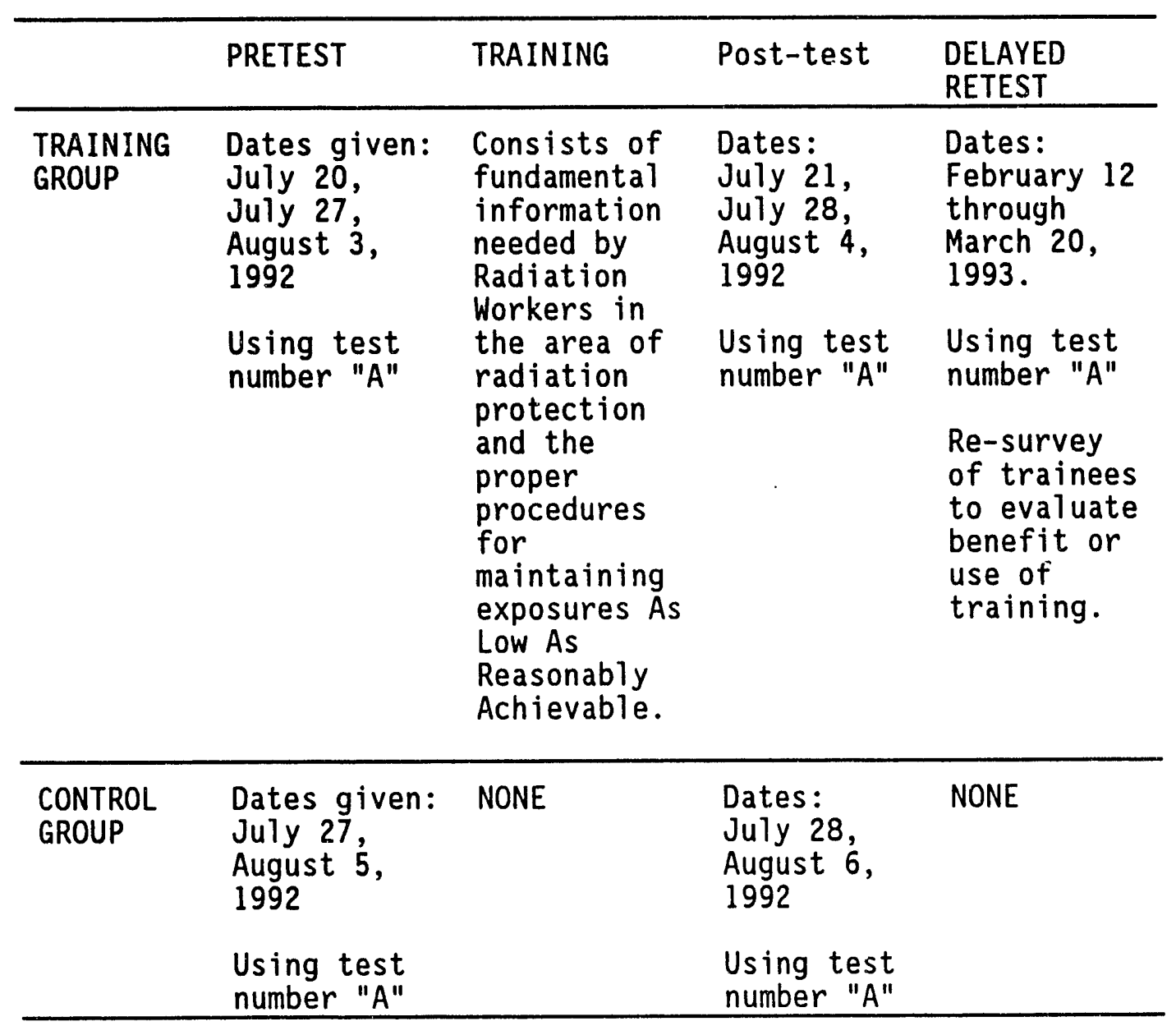


In addition to the training and the tests, the trainees were asked to complete a short survey (see Appendix C) when they took the delayed 6 month post-test to ascertain the use of the training in their on-the-job experiences and the number of times that they had entered a radiation zone within that time.

No direct on-the-job observation measures were available at the time of this study. To provide a basis for the establishment of a Level 3 measurement, a critical incident questionnaire (see Appendix D) was mailed to approximately 60 subject matter experts, requesting data on both effective and non-effective performance behaviors for radiation workers.

Subsequently, feedback was provided to the technical training group on the effectiveness of the radiation safety training. Feedback included evaluations of the trainee attitude data, the pre-test, the post-test, delayed post-test results, and results of the critical incident questionnaire. 
WHC-MR-0383

\section{CHAPTER IV}

Resuits

Resulits are organized according to two levels of the Kirkpatrick criteria: reaction criteria and learning criteria. On-the-job behavior criteria and outcome criteria were not measured at this study. The reactions consist of the immediate evaluations by the trainees of the course content. The learning measure consisted of the cognitive test results. Verbal selfreports provide the results of the survey questionnaire administered in March, and some measurement of on-the-job behavior. Development of on-the-job behavior measures were evaluated, based on the test questions and information from the critical incident questionnaire.

\section{Trainee Reaction Data}

Table 2 summarizes initial trainee reactions to the course and the material presented. Twenty-eight of the trainees filled out course evaluation sheets, answering the following questions on a four point scale: 1 = poor, 2 = fair, 3 = very good and 4 = excelıent. Table 2 summarizes trainee reactions to seven dimensions from the training session in descending frequency of occurrence. Additional trainee evaluation data were gathered by collating the answers to three more questions. The trainees were asked if they felt that they needed additional information about the topic. Two answered "yes," 24 answered "no," and 2 provided no response. Another question asked the trainees about the utility of the course material to their work. Fifteen responded that they felt the subject matter that was covered was "extremely useful." Another 13 responded that they felt the subject matter covered was "useful." None responded that the subject matter covered might prove "unusable" in their work. 
WHC-MR-0383

Table 2.

Responses from Trainee Questionnaire, Questions 1-7

\begin{tabular}{|c|c|c|c|c|c|c|}
\hline \multirow[b]{2}{*}{ Dimensions } & \multicolumn{4}{|c|}{ Response Frequency * } & \multirow{2}{*}{ Mean } & \multirow{2}{*}{$\begin{array}{l}\text { Std } \\
\text { Dev }\end{array}$} \\
\hline & 1 & 2 & 3 & 4 & & \\
\hline $\begin{array}{l}\text { Effectiveness of } \\
\text { teaching method: }\end{array}$ & 1 & 1 & 18 & 8 & 3.18 & 0.66 \\
\hline $\begin{array}{l}\text { Clarity of course } \\
\text { objectives: }\end{array}$ & 0 & 2 & 18 & 8 & 3.21 & 0.56 \\
\hline $\begin{array}{l}\text { Instructor's command of } \\
\text { subject: }\end{array}$ & 0 & 2 & 14 & 12 & 3.36 & 0.61 \\
\hline $\begin{array}{l}\text { Opportunity for } \\
\text { interaction: }\end{array}$ & 0 & 3 & 15 & 10 & 3.25 & 0.63 \\
\hline Activities presented: & 0 & 3 & 18 & 7 & 3.14 & 0.58 \\
\hline Materials provided: & 0 & 6 & 18 & 4 & 2.93 & 0.59 \\
\hline $\begin{array}{l}\text { Organization of the } \\
\text { ccurse: }\end{array}$ & 0 & 3 & 18 & 7 & 3.14 & 0.58 \\
\hline
\end{tabular}

* Dimensians were rated on a 4 point scale: 1 = Poor, 2 = Fair, 3 = Very Good, $4=$ Excellent 
Another question that the trainees responded to concerned the level at which they felt the subject content to be. Three responded that the subject sontent was "too elementary." The other 25 responded that the subject content wa's "just right." None responded that the content was "too advanced."

The only question of the 3 that had a real division in response was question 9, with respondees divided between "extremely useful" (15) and "useful" (13) on the subject of the future utility of the course material. The stated lack of need for additional information, coupled with the responses that the course subject matter and content were at an appropriate level indicates to a high degree the adequacy of the course material.

Table 3 lists additional responses to the request for any further comments on the course from the trainees. This information has been organized into a frequency count of the discussion by the trainees of both major strong and/or weak points of the course. Additional information was gathered from the responses to "other comments." The final request was for an overall trainee evaluation of the course. Of the 28 respondees, 11 responded that "overall the course was very good," 7 had no response at al1, 6 answered "good," and "excellent," "great," "well done," and "fair" each earned one response. The responses were weighted from 1 (no answer) to 7 (excellent). The overall evaluation of the course was between "good" and "very good" $(\underline{M}=3.54, \underline{S D}=2.23)$.

\section{Cognitive Test Data}

The means and standard deviations from the pretest, post-test and delayed post-test cognitive data across groups are shown in Table 4 and represented graphically in Table 5. The scores across groups are shown in Appendix $B$. No significant difference was shown between the groups in the pretest, but a significant difference was obtained between the training group 
WHC-MR-0383

Table 3.

Comments from Trainee Evaluation Sheets, July-August 1992

Comments

Frequency

Instructor very knowledgeable and helpful

Good practical examples and hands-on exercise

Course we11 organized

5

Taught initial points about radiation worker needs

4

Some test questions were poor, fuzzy, not covered

4

during training, marked wrong on key

Little perspective presented on radiation levels,

curies, contamination levels

Would like a chart with dose rate limits

Would Tike hand outs on radiation postings 3

Course notes will be good reference material 2

The figure on requirements to enter a Radiologically 2

Controlled Area (RCA) is not consistent with the lecture

Need more information on Radiation Work Permits (RWPs) 2

Need to cover some actual plant events 2

Want conduct of operations covered 2

Additional instructors not needed 1

Very little factual information on risks of low-level 1 doses 
WHC-MR-0383

Table 3.

Comments from Trainee Evaluation Sheets, July-August 1992.

(Continued)

Comments Frequency

The course seems too long (2 days) 1

Too much information - overload 1

Having to pass exams is a problem 1

Room too cold 1

Course too dull - just follows routine 1

Draft material weak 1

Would like to take a competency exam 1

Want more detailed general information 1

Want practical training in frisking 1

Define new words early in course 1 
WHC-MR-0383

Table 4.

Means and Standard Deviations Across Groups

\begin{tabular}{lllllll}
\hline & \multicolumn{3}{c}{ Training } & \multicolumn{3}{c}{ Control } \\
\cline { 2 - 7 } & N & Mean & SD & N & Mean & SD \\
& & & & & & \\
\hline Pretest & 39 & 35.90 & 4.94 & 15 & 36.00 & 3.32 \\
Post-test & 39 & 45.90 & 2.98 & 15 & 36.20 & 3.12 \\
Delayed Post-test & 10 & 42.00 & 4.03 & N/A & N/A & N/A \\
& & & & & & \\
\hline
\end{tabular}


WHC-MR-0383

Table 5.

Mean Test Scores in Graph Form

Protent Post-tent Doleyed Retest

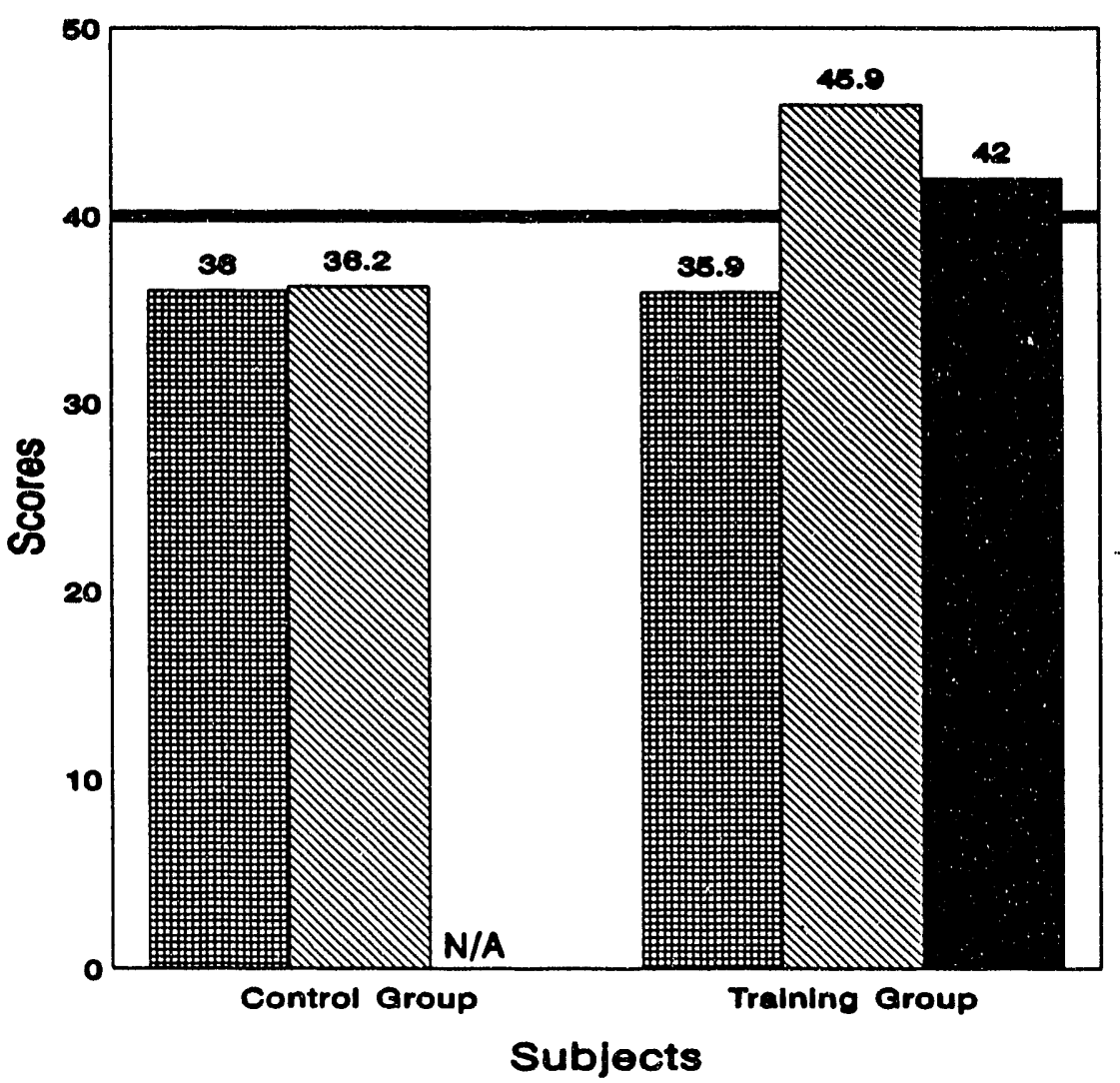


and the control group at the post-test. Although the delayed post-test mean of the training group decreased significantly, it was still higher than the pretest mean. The total possible points that could be scored was 50 . The minimum proficiency level was 40 .

Cognitive test scores were compared as follows: the two groups were compared by using a $\underline{t}$-test, and that information is provided in Table 6 . The results are significant, with the training effecting a $p$ value of $<0.001$ for the post-test and delayed post-test scores of the training group. No significant difference was found in the pretest scores.

\section{On the Job Self-Report Data}

At the time of the delayed post-test, the trainees were asked to further evaluate the utility of the course, the number of times that they had actually entered a radiation area, and whether they felt the course had provided them with information that would help them work safely. This information was collected on the survey form shown in Appendix $C$.

The demographics showed that 9 males and 1 female took the delayed post-test. Eight of the personnel are professional staff, and 2 are management. Of these personnel, none accessed radiation areas daily, 3 needed access weekly, 1 entered the areas monthly, 3 entered less than monthly, and 3 of the personnel had not entered a radiation area at all in the past 6 months $(\underline{M}=3.6, \underline{S D}=1.2)$.

The results show that the course material was categorized as useful, with 1 person strongly agreeing, 7 agreeing, none disagreeing, and 2 strongly disagreeing $(\underline{M}=2.7, \underline{S D}=0.9)$. This corresponds with the other question on utility about the frequency that the class information is used. None of the respondents used the information to a very great extent. Three used the 
Table 6.

Comparison of Cognitive Test Scores

\begin{tabular}{lccc}
\hline \multicolumn{1}{c}{ Comparison } & $\mathrm{t}$ & $\mathrm{df}$ & $\mathrm{p}$ \\
\hline Pretest: & & & \\
Training vs. Control Group & 0.13 & 52 & 0.90 \\
Post-Test: & & & \\
Training vs. Control Group & 10.35 & 52 & $<.001$ \\
Post-test: & & & \\
Training Group & & & \\
Immediate vs. Delayed & & 9 & \\
(6 month) & 5.60 & & \\
\end{tabular}


information to a great extent, 3 used it to some extent, 2 used it to a 1 ittle extent, and 2 of the personnel used the information to a very little extent $(\underline{M}=2.7, \underline{S D}=1.1)$.

Nine of the 10 respondents felt that the course material had helped them become safer workers. One of the respondents answered "not sure," commenting that he had not had an opportunity to use the information from the course while on the job. This person had not entered a radiation area in the past 6 months.

On a scale of 5 (perfectly satisfied) to 1 (not at all satisfied), the respondents rated the training received in the class with 1 person rating it a 5,7 rating it a 4 , and 2 people rating the course as a $3(\underline{M}=3.9$, $\underline{S D}=.54)$. Development of On-the-Job Measures

At the time of the study there were no direct observational measures of on-the-job behavior of the training group. To provide the basis for a prototype level 3 evaluation method, a modified critical incident questionnaire (see Appendix D) was used. This questionnaire was sent out to subject matter experts, Health Physics professionals, and 10 responded. The subject matter experts were requested to 1 ist from one to five effective behaviors that they had previously observed in radiation workers, and from one to five ineffective behaviors. From those replies, a frequency table of effective and ineffective behaviors was developed (see Table 7). Behavioral dimensions of radiation workers were developed from the replies, and listed by frequency of response.

With respect to the cognitive pretest, post-test, and delayed post-test data, Appendix $E$ is a list of all the question numbers on the test, and the number of misses for each. This provides a view of all answers from both 
WHC-MR-0383

Table 7.

Behavioral Dimensions Resulting from the Critical Incident Data

Dimensions

Frequency

of Response

Procedures followed

13

Entry and egress procedures properly done

6

Proper training on dose rates, dosimetry, know

difference between radiation and contamination

6

Follow proper dress and undress practices

5

Use proper safety equipment

4

Notify other personnel in area of any problems, unsafe conditions, alarms, timekeeping issues

Utilize support personnel when needed 2

Prepare documentation properly 2

Follow the requirements of the Radiation Work Permits 2

Provide effective management and communication for radiation workers

2

Follow the requirements of the work packages 
groups for the pretest, post-test and the delayed post-test. Table 8 lists those questions missed most frequently both before and after training, and relates to the behavioral dimensions listed in Table 7 .

The critical incident responses were primarily concerned with procedural violations, lack of practical knowledge of radiation practices and a lack of knowledge about radiation dose rates and zone entries. The questions most often missed, both before and after training, were concerned with issues of dose rates, dosimetry, procedures, practical applications of monitoring, and various posting issues. The trainees consistently missed these questions, and the questions were missed again during the delayed post-test, which is significant. Questions number 1,12 , and 31 (dose rates or dosimetry issues) each had a $50 \%$ failure on the delayed post-test.

The number of times that the personnel entered the radiation zone was calculated from their responses to the delayed post-test survey. of the 10 trainees, 6 rarely enter an area (infrequently or not at a11).

The majority of the questions missed deal with radiation doses and dosimetry issues. Fetal dose rates, sources of common dose rates to the general public, whole body counting, bioassay and use of dosimetry and dose treatment. Posting and radiation zones are also issues which are missed frequently on the tests. These are also matters of procedural issues.

The information from the critical incident survey relates strongly to these same issues. The subject matter experts (Health Physics professionals) recognize the need for radiation worker knowledge in the areas of dosimetry, procedurès and processes, zone entry requirements and general knowledge of contamination levels and acceptable dose rates. These same issues were missed with great frequency before the training, after the training session and again after the 6 month delayed post-test. 
Table 8.

Test Areas Most Frequently Missed

Number and Percentages Missed.

$\overline{\text { Pretest }}$ Post-Test Delayed

Test Area

Post-Test

$$
\underline{\mathrm{n}}=54 \quad \underline{\mathrm{n}}=10
$$

\begin{tabular}{llll}
\hline Fetal dose 1imits & $33(61 \%)$ & $8(15 \%)$ & $8(80 \%)$ \\
General public doses & $34(63 \%)$ & $22(41 \%)$ & $7(70 \%)$ \\
Contamination levels & $45(83 \%)$ & $38(70 \%)$ & $7(70 \%)$ \\
Procedural issues & $48(89 \%)$ & $38(70 \%)$ & $6(60 \%)$ \\
Posting issues & $38(70 \%)$ & $15(28 \%)$ & $6(60 \%)$ \\
Dosimeter use & $49(91 \%)$ & $14(26 \%)$ & $5(50 \%)$ \\
Posting issues & $26(48 \%)$ & $14(26 \%)$ & $5(50 \%)$ \\
Radiation doses & $25(46 \%)$ & $20(37 \%)$ & $5(50 \%)$ \\
Population dose rates & $21(38 \%)$ & $9(17 \%)$ & $5(50 \%)$ \\
Survey practices & $29(54 \%)$ & $23(43 \%)$ & $4(40 \%)$ \\
Contamination levels & $32(59 \%)$ & $14(26 \%)$ & $4(40 \%)$ \\
Dose control levels & $40(74 \%)$ & $12(23 \%)$ & $2(20 \%)$ \\
\hline
\end{tabular}


WHC-MR-0383

\section{CHAPTER V}

Discussion

The purpose of this study was to evaluate the effectiveness of the Radiation Worker Safety Training course at a nuclear facility and to provide feedback to the technical training group for use in future training. The radiation worker training class was chosen for the study because of the importance that it has in the training at the nuclear facility. It is a course required for those workers who access radiation zones or areas. The goal of the study was to provide information on the transfer of learning from the classroom to actual on-the-job behavior. Although this study does not accomplish that goal, it does provide the basis for development of measures which may be used in a level 3 evaluation.

\section{Evaluation Approach}

The four levels of training criteria suggested by Kirkpatrick (1976) guided the design of this study. The first two phases of the study (trainee evaluations and cognitive test results) were accomplished easily. The third criterion suggested by Kirkpatrick, on-the-job behavior, should be done by means of actual observation or interviews of those personnel who had access to observe the work behavior of the trainees, in addition to trainee self-report data. Information was collected from 10 of the trainees by means of a survey 6 months after the initial course work. These data provided further trainee evaluation of the course material and how useful on the job they felt that it was to them.

The accuracy of verbal self reporting has been questioned in the past and is not fully known. Studies have shown inconsistent results in the accuracy of personal estimation of ability (Mabe and West 1982). Verbal self 
report can be used very effectively for some stringent demographics such as entry data--how many times one has entered a radiation zone. The answers to the question of the perceived increase in safe behavior by the individual, based on the training received, were also of value, even discounting some personal biases that may have prompted the responses. The individuals in this case responded in the majority that the training had made them safer workers. Additionally, not all of the original trainees were available for the delayed post-test and the survey. Ten of the trainees were no longer on the nuclear site, and of the 29 remaining, 19 chose not to be retested or provide further information, since this was strictly voluntary. This is significant in that the trainees should have this knowledge, but do not seem to retain it as well as other issues that they are trained in. These issues are discussed by the subject matter experts as information that the trainees should have.

The fourth of Kirkpatrick's criteria refers to outcomes. There were no outcomes examined in this study, including a return on investment to the company due to reduced safety infractions or reduced absenteeism or reduced loss of time due to fewer accidents.

The self-reports of the trainees were examined and evaluated with the results of the test questions in relation to the behaviors recommended by the subject matter experts in the critical incident questionnaire. Overall, these results by verbal self report speak to a general satisfaction with the course material as far as utility on the job and providing personnel with strong safety training. The number of times that the personnel access the areas influenced their answers on the utility of the course, but the safety factor was recognized by all with the exception of one person who specifically related the safety issue to an access issue. 
WHC-MR-0383

\section{Conclusion and Recommendations}

The pretest results showed no significant difference between the training group and the control group. The two groups were equivalent. When posttested, however, there was a significant difference between the training group and the control group, indicating that the training did have an effect.

There was a significant difference between the immediate and delayed post-tests. The delayed post-test showed a drop in the mean of the training group by some points to just abuo the 40 points established as the proficiency level. This would indicate that the training did have an effect, and the transfer of learning was still notable after six months. However, while the mean of the delayed post-test was significantly higher than the mean of the pretest, the significant drop in means from the post-test to the delayed post-test indicates that there may be a need for more frequent refresher courses in order to maintain the transfer of learning levels.

Some of the questions were consistently missed, both before and after training, indicating either that the training should be strengthened in those areas or that the questions should be reevaluated for clarity. The overall average scores did improve, and there were fewer misses on all questions posttraining. While the object of the course is certainly to provide training that will enable the participants to pass the required test, it is valuable to note the questions that posed problems for the trainees, and to evaluate the training that is necessary for the trainees to fully understand the information that they are receiving. If, for instance, some questions on the tests are posing difficulties even after the training, the training for that area may not be as adequate, for whatever reason, as would be preferred.

Several issues were missed noticeably both during the pretest, after training during the post-test, and after the 6 month interval before the 
delayed post-test. This would indicate a need for technical training to look at those areas with an eye to improving the communication to the trainee. The subject matter experts responding to the critical incident questionnaire were adamant in the reed for very specific behaviors in such areas as following zone entry requirements, use of dose rate knowledge and dosimetry, following procedures, and following posting requirements. These criteria related to the requests by the trainees for further information (from the original evaluation sheet) and obvious misses on the test.

Another area that may be explored is the format of the question itself. Possibly the wording of the questions could be causing misses, and if this is the case, rewording the questions may resolve the problem. Technical training should also clarify the time they need to spend on areas of generally well known data, and consider decreasing time spent in those areas in order to provide more time for the issues that are consistently problem areas.

This balancing of training time and method may provide improvement on those questions that seem to be missed more frequently: for even though the trainee has passed with a score of $40+$, the missed questions may pose problems in actual performance, and this certainly requires further evaluation. Additional information should be sought from other sources for on the job performance. Frequency of accidents might be measured against the training goals. various databases are available at the nuclear facility which would allow correlation of personnel data with the training issues raised.

A suggestion for further research in this area would be to observe actual on-the-job behaviors and performance in addition to interviews. Perceived deficiencies in performance or safety may not be due to training 
inadequacies, but may be a result of other influences. Employee involvement in the safety system and management support of their efforts should be investigated as a force in training application (Lawler 1985).

A further suggestion would be to perform a return on investment study for the courses under evaluation. This would certainly provide the organization with a benchmark for training utility and cost effectiveness. However, utility and return on investment of training analysis will require a valid measure of on the job performance changes resulting from the training. Thus, future researchers would be able to provide the organization greater detail in the evaluation, and broaden the scope of results. Level 4 of the Kirkpatrick criteria suggests results that provide return on investment for the company in terms of the benefits of decreased absenteeism, reduced accidents, increased attention to safety measures and reduced turnover. This study did not collect that data nor make that evaluation. The course has been changed since the study was initiated, and the return on investment should be done for future evaluations. 


\section{REFERENCES}

Bandura, A., 1977, "Self-Efficacy: Toward a Unifying Theory of Behavioral Change," Psychological Review, 84, pp. 191-215.

Brandenburg, D. C., 1989, "Evaluation and Business Issues: Tools for Management Decision Making," Evaluating Training Programs in Business and Industry, Jossey-Bass, San Francisco, California, pp. 83-99.

Brinkerhoff, R. 0., 1989, "Using Evaluation to Transform Training," Evaluating Training Programs in Business and Industry, Jossey-Bass, San Francisco, California, pp. 5-19.

Cheng, P. W., K. J. Holyoak, 1985, "Pragmatic Reasoning Schemas," Cognitive Psychology, 17, pp. 391-416.

Feiza, A. S., R. W. Klemm, 1987, "Evaluating Performance Measures to Determine Training Effectiveness," Proceedings of the CSNI Specialist Meeting on Training of Nuclear Reactor Personnel, (Nuclear Energy Agency, 75 Paris, (France) Committee on the Safety of Nuclear Installations), pp 390-396.

Geiwiz, J., V. A. Spiker, D. H. Harris, 1988, Handbook for Evaluating the Proficiency of Maintenance Personne7, NP-5710, Research Project 2705, Anacapa Sciences, Inc., Santa Barbara, California.

Gi11, S. J., 1989, "Using Evaluation to Build Commitment to Training," Evaluating Training Programs in Business and Industry, Jossey-Bass, San Francisco, California, pp. 35-42.

Gordon, J., 1991, "Measuring the Goodness of Training," Training, August 1991.

Kirkpatrick, D. L., 1976, "Evaluation of Training," Training and Development Handbook: A Guide to Human Resource Development, McGraw-Hi11, New York, New York.

Lawler III, E. E., 1985, "Education, Management Style, and Organizational Effectiveness," Personnel Psychology, 38, pp. 1-26.

Mabe II, P. E., S. G. West, 1982, "Validity of Self-Evaluation of Ability: A Review and Meta-Analysis," Journal of Applied Psychology, 67, pp. 280-296.

McElroy, N., A. Brodsky, 1986, "Training Manual for Uranium Mill Workers on Health Protection from Uranium, "Division of Radiation Programs and Earth Sciences, Office of Nuclear Regulatory Research, U.S. Nuclear Regulatory Commission, Washington, D.C. 20555.

Nowakowski, A. C., 1989, "Strategy for Internal Evaluators," Evaluating Training Programs in Business and Industry, Jossey-Bass, San Francisco, California, pp. 45-57. 
Peter, F., 1990, "Danger! Unsupported Roof," Coa7, pp. 60-63.

Russe11, N. M., J. R. Terborg, and M. L. Powers, 1985, "Organizational Performance and Organizational Level Training and Support," Personnel Psychology, 38, pp. 849-863.

Saal, F. E. and P. A. Knight, 1988, Industrial/Organizational Psychology, Science and Practice, Brooks/Coal Publishing Company, Pacific Grove, California.

Sanders, N. M., 1989, "Evaluation of Training by Trainers," Evaluating Training Programs in Business and Industry, Jossey-Bass, San Francisco, California, pp. 45-57.

Shapiro, J., 1990, Radiation Protection: A Guide for Scientists and Physicians, Third Edition, Cambridge, Massachusetts.

Swanson, R. A., 1989, "Everything Important in Business and Industry is Evaluated," Evaluating Training Programs in Business and Industry, Jossey-Bass, San Francisco, California, pp. 71-82.

Tannenbaum, S. I., J. E. Mathieu, E. Salas, and J. A. Cannon-Bowers, 1991, "Meeting Trainees' Expectations: The Influence of Training Fulfillment on the Development of Commitment, Self-Efficacy, and Motivation," Journal of Applied Psychology, 76, pp. 759-769.

Vinther, R. W., 1991, Evaluation of M-101 Managing Occupational Safety in DOE Courses, Pacific Northwest Laboratory, Richland, Washington.

Vinther, R. W., 1991, Evaluation of M-101 Orientation to Occupational Safety Compliance in DOE Pilot Course, Pacific Northwest Laboratory, Richland, Washington.

Wexley, K. N., G. P. Latham, 1991, Developing and Training Human Resources in Organizations, 2nd Edition, Harper/Collins. 
WHC-MR-0383

Appendix A

Course Evaluation Sheet Safety Training

\begin{tabular}{|c|c|c|c|c|}
\hline Question & Poor & Fair & $\begin{array}{l}\text { Very } \\
\text { Good }\end{array}$ & $\begin{array}{l}\text { Exce 1- } \\
\text { lent }\end{array}$ \\
\hline $\begin{array}{l}\text { 1. Effectiveness of the teaching method } \\
\text { was: }\end{array}$ & & & & \\
\hline 2. Clarity of course objectives was: & & & & \\
\hline 3. Instructor's command of subject was: & & & & \\
\hline 4. Opportunity for interaction was: & & & & \\
\hline 5. Activities presented were: & & & & \\
\hline 6. Materials provided were: & & & & \\
\hline 7. Organization of the course was: & & & & \\
\hline
\end{tabular}

8. Do you need additional information about the topic? Yes_No

9. Subject matter covered will be: Extremely useful__ Useful__ Just Right

10. Subject content was:

Too Elementary___ Just Right___ Too Advanced

11. Major strong points of the course were:

1 .

2.

12. Major weak points of the course were:

1.

2.

13. Overall the course was: 14. Other comments 
WHC-MR-0383

Appendix B

Test Scores

\begin{tabular}{|c|c|c|c|c|}
\hline & Subjoct & Protost & Post-test & Delayod Tost \\
\hline$T$ & A1 & 41 & 48 & $N / A$ \\
\hline $\mathbf{R}$ & A2 & 30 & 46 & $N / A$ \\
\hline A & A3 & 35 & 47 & N/A \\
\hline 1 & A4 & 25 & 44 & N/A \\
\hline $\mathbf{N}$ & A5 & 41 & 50 & 43 \\
\hline $\mathbf{E}$ & A6 & 35 & 43 & N/A \\
\hline \multirow[t]{3}{*}{$D$} & A7 & 37 & 47 & 47 \\
\hline & $A 8$ & 39 & 43 & N/A \\
\hline & A9 & 33 & 3.9 & $N / A$ \\
\hline $\mathbf{s}$ & A10 & 35 & 4.9 & N/A \\
\hline$u$ & A11 & 38 & 47 & N/A \\
\hline B & A12 & 47 & 48 & $N / A$ \\
\hline$J$ & A13 & 38 & 47 & 45 \\
\hline$E$ & A14 & 34 & 41 & N/A \\
\hline c & A15 & 33 & 45 & N/A \\
\hline$T$ & A16 & 38 & 47 & N/A \\
\hline \multirow[t]{3}{*}{$\mathbf{s}$} & A17 & 37 & 50 & N/A \\
\hline & A18 & 36 & 48 & 39 \\
\hline & A19 & 26 & 40 & N/A \\
\hline$T$ & A20 & 42 & 50 & N/A \\
\hline $\mathbf{R}$ & A21 & 39 & 50 & N/A \\
\hline A & A 22 & 44 & 50 & N/A \\
\hline 1 & A23 & 34 & 47 & N/A \\
\hline$N$ & A24 & 26 & 43 & 38 \\
\hline $\mathbf{E}$ & A 25 & 32 & 46 & N/A \\
\hline \multirow[t]{2}{*}{$D$} & A26 & 30 & 44 & 36 \\
\hline & A27 & 37 & 45 & N/A \\
\hline $\mathbf{s}$ & A28 & 36 & 48 & N/A \\
\hline$u$ & A29 & 34 & 42 & $N / A$ \\
\hline$B$ & A30 & 41 & 50 & 45 \\
\hline $\mathrm{J}$ & A31 & 31 & 44 & 38 \\
\hline$E$ & A32 & 44 & 49 & 42 \\
\hline$C$ & A33 & 38 & 45 & N/A \\
\hline
\end{tabular}


WHC-MR-0383

\begin{tabular}{|c|c|c|c|c|}
\hline & Subjoct & Pretest & Post-test & Delayed Tost \\
\hline$T$ & A34 & 31 & 43 & N/A \\
\hline \multirow[t]{5}{*}{$\mathbf{s}$} & A35 & 36 & 47 & N/A \\
\hline & A36 & 41 & 48 & 47 \\
\hline & A37 & 37 & 43 & N/A \\
\hline & A38 & 34 & 45 & N/A \\
\hline & A39 & 33 & 43 & N/A \\
\hline $\mathbf{N}$ & $x_{1}$ & 34 & 35 & N/A \\
\hline \multirow[t]{2}{*}{0} & $\times 2$ & 35 & 38 & N/A \\
\hline & $\times 3$ & 32 & 31 & N/A \\
\hline$T$ & $x 4$ & 41 & 42 & N/A \\
\hline R & $\times 5$ & 35 & 35 & N/A \\
\hline A & $\times 6$ & 33 & 36 & N/A \\
\hline 1 & $x 7$ & 36 & 33 & N/A \\
\hline $\mathbf{N}$ & $\times 8$ & 36 & 33 & N/A \\
\hline 1 & $\times 9$ & 40 & 40 & N/A \\
\hline $\mathrm{N}$ & $\times 10$ & 40 & 40 & N/A \\
\hline \multirow[t]{5}{*}{ G } & $x 11$ & 30 & 33 & N/A \\
\hline & $\times 12$ & 40 & 37 & N/A \\
\hline & $\times 13$ & 33 & 35 & N/A \\
\hline & $\times 14$ & 38 & 36 & N/A \\
\hline & $\times 15$ & 37 & 39 & N/A \\
\hline
\end{tabular}




\section{Appendix C \\ POST TRAINING EVALUATION SAFETY TRAINING}

For each of the following questions, please circle the ONE number which best indicates your response.

1. Gender: Male___ Female

2. How often in the past 6 months have you entered a Radiation Zone?
a. Not at all
b. Infrequently (less than monthly)
c. Daily
d. Weekly
e. Monthiy

3. The information that I received in the Rad Worker Safety Training Class has been useful to me in my job.
a. Strongly agree
b. Agree
c. Disagree
d. Strongly Disagree

4. My job category is:
a. Management
b. Professional
c. Clerical/Secretarial
d. Technical.

5. I feel that the training has helped me become a safer worker: Yes Not Sure

6. On a scale from 5) to 1), how satisfied are you with the training that you received in this class?
5) Perfectly Satisfied
4)
3)
2)
1) Not at all satisfied. 
WHC-MR-0383

Appendix C Continued.

7. I use the information that I received in the class

a. To a very great extent

b. To a great extent

c. To some extent

d. To a little extent

e. To a very little extent.

COMMENTS : 


\section{Appendix D \\ Radiation Worker Safety Training Evaluation \\ Questionnaire}

You are in a position to frequently observe the people in this job, and you are aware of the aims and objectives of the job. Therefore, you are able to discern safe behavior from unsafe behavior. Please do not tell me the names of any individual to whom you are referring.

Please think back over the last 6-12 months of specific work behavior exhibited by your employees that you yourself have observed which would promote radiological safety in the workplace. There are 3 questions to answer for each incident; please write your answers in the spaces provided below. If you have trouble thinking of incidents, think about 5 key things an employee inust be good at and do in this job which would promote safety and prevent accidents. Then, think of an employee who within the past year demonstrated each point.

1. Effective Incident - the type of behavior you wish all employees would perform. What were the circumstances surrounding this incident? What was the situation?

What exactly did the individual do that was effective?

How is this incident an example of effective behavior? In other words, how did this affect the task the individual was performing? 
Appendix D Continued.

2. Effective Incident - the type of behavior you wish all employees would perform. What were the circumstances surrounding this incident? What was the situation?

What exactly did the individual do that was effective?

How is this incident an example of effective behavior? In other words, how did this affect the task the individual was performing?

3. Effective Incident - the type of behavior you wish all employees would perform. What were the circumstances surrounding this incident? What was the situation?

What exactly did the individual. do that was effective? 
Appendix D Continued.

How is this incident an example of effective behavior? In other words, how did this affect the task the individual was performing?

4. Effective Incident - the type of behavior you wish all employees would perform. What were the circumstances surrounding this incident? What was the situation?

What exactly did the individual do that was effective?

How is this incident an example of effective behavior? In other words, how did this affect the task the individual was performing?

5. Effective Incident - the type of behavior you wish all employees would perform. What were the circumstances surrounding this incident? What was the situation?

What exactly did the individual do that was effective? 
Appendix D Continued.

How is this incident an example of effective behavior? In other words, how did this affect the task the individual was performing?

1. Ineffective Incident - behavior which would make you doubt the competency of the individual.

What were the circumstances surrounding this incident? What was the situation?

What exactly did the individual do that was ineffective?

How is this incident an example of ineffective behavior? In other words, how did this affect the task the individual was performing?

2. Ineffective Incident - behavior which would make you doubt the competency of the individual.

What were the circumstances surrounding this incident? What was the situation?

What exactly did the individual do that was ineffective? 
Appendix D Contirued.

How is this incident an example of ineffective behavior? In other words, how did this affect the task the individual was performing?

3. Ineffective Incident - behavior which would make you doubt the competency of the individual.

What were the circumstances surrounding this incident? What was the situation?

What exactly did the individual do that was ineffective?

How is this incident an example of ineffective behavior? In other words, how did this affect the task the individual was performing?

4. Ineffective Incident - behavior which would make you doubt the competency of the individual.

What were the circumstances surrounding this incident? What was the situation?

What exactly did the individual do that was ineffective? 
Appendix D Continued.

How is this incident an example of ineffective behavior? In other words, how did this affect the task the individual was performing?

5. Ineffective Incident - behavior which would make you doubt the competency of the individual.

What were the circumstances surrounding this incident? What was the situation?

What exactly did the individual do that was ineffective?

How is this incident an example of ineffective behavior? In other words, how did this affect the task the individual was performing? 
WHC-MR-0383

Appendix E

Number of Misses per Question on Test

\begin{tabular}{|c|c|c|c|c|c|}
\hline Question & $\begin{array}{l}\text { Training } \\
\text { Pretest } \\
n=39\end{array}$ & $\begin{array}{l}\text { Training } \\
\text { Post-test } \\
n=39\end{array}$ & $\begin{array}{l}\text { Training } \\
\text { Retest } \\
n=10 \\
\end{array}$ & $\begin{array}{l}\text { Control } \\
\text { Pretest } \\
n=15\end{array}$ & $\begin{array}{l}\text { Control } \\
\text { Post-test } \\
n=15\end{array}$ \\
\hline 1 & 37 & 2 & 5 & 12 & 12 \\
\hline 2 & 30 & 2 & 2 & 10 & 11 \\
\hline 3 & 0 & 0 & 0 & 1 & 1 \\
\hline 4 & 5 & 3 & 0 & 2 & 1 \\
\hline 5 & 9 & 6 & 0 & 4 & 4 \\
\hline 6 & 3 & 0 & 0 & 0 & 1 \\
\hline 7 & 10 & 2 & 0 & 5 & 6 \\
\hline 8 & 7 & 3 & 0 & 3 & 1 \\
\hline 9 & 6 & 0 & 0 & 2 & 2 \\
\hline 10 & 2 & 1 & 0 & 1 & 1 \\
\hline 11 & 11 & 1 & 0 & 0 & 6 \\
\hline 12 & 14 & 1 & 5 & 7 & 8 \\
\hline 13 & 4 & 0 & 1 & 1 & 3 \\
\hline 14 & 35 & 27 & 6 & 13 & 11 \\
\hline 15 & 2 & 0 & 1 & 3 & 2 \\
\hline 16 & 6 & 1 & 0 & 0 & 2 \\
\hline 17 & 28 & 15 & 7 & 6 & 7 \\
\hline 18 & 2 & 1 & 0 & 0 & 0 \\
\hline 19 & 7 & 3 & 2 & 4 & 5 \\
\hline 20 & 18 & 4 & 4 & 6 & 7 \\
\hline 21 & 25 & 2 & 8 & 8 & 6 \\
\hline 22 & 7 & 1. & 1 & 4 & 3 \\
\hline 23 & 2 & 1 & 0 & 0 & 0 \\
\hline 24 & 1 & 0 & 0 & 0 & 0 \\
\hline 25 & 8 & 1 & 1 & 2 & 1 \\
\hline 26 & 1 & 0 & 0 & 2 & 1 \\
\hline
\end{tabular}


WHC-MR-0383

\begin{tabular}{|c|c|c|c|c|c|}
\hline Question & $\begin{array}{l}\text { Training } \\
\text { Pretest } \\
n=39\end{array}$ & $\begin{array}{l}\text { Training } \\
\text { Post-test } \\
n=39\end{array}$ & $\begin{array}{l}\text { Training } \\
\text { Retest } \\
n=10 \\
\end{array}$ & $\begin{array}{l}\text { Control } \\
\text { Pretest } \\
n=15\end{array}$ & $\begin{array}{l}\text { Control } \\
\text { Post-test } \\
n=15\end{array}$ \\
\hline 27 & 1 & 0 & 1 & 2 & 0 \\
\hline 28 & 9 & 3 & 0 & 1 & 4 \\
\hline 29 & 0 & 0 & 0 & 1 & 1 \\
\hline 30 & 1 & 0 & 0 & 0 & 0 \\
\hline 31 & 19 & 13 & 5 & 6 & 7 \\
\hline 32 & 13 & 0 & 2 & 7 & 4 \\
\hline 33 & 24 & 5 & 4 & 8 & 9 \\
\hline 34 & 7 & 0 & 0 & 2 & 2 \\
\hline 35 & 16 & 0 & 0 & 5 & 6 \\
\hline 36 & 24 & 17 & 1 & 9 & 8 \\
\hline 37 & 19 & 11 & 4 & 10 & 12 \\
\hline 38 & 11 & 0 & 0 & 4 & 5 \\
\hline 39 & 11 & 1 & 0 & 5 & 3 \\
\hline 40 & 1 & 0 & 0 & 1 & 1 \\
\hline 41 & 3 & 0 & 0 & 1 & 0 \\
\hline 42 & 18 & 5 & 5 & 8 & 9 \\
\hline 43 & 33 & 25 & 7 & 12 & 13 \\
\hline 44 & 26 & 4 & 6 & 12 & 11 \\
\hline 45 & 0 & 0 & 0 & 0 & 0 \\
\hline 46 & 5 & 0 & 0 & 0 & 0 \\
\hline 47 & 0 & 0 & 0 & 1 & 0 \\
\hline 48 & 25 & 2 & 3 & 10 & 7 \\
\hline 49 & 3 & 1 & 0 & 1 & 3 \\
\hline 50 & 0 & 0 & 0 & 0 & 1 \\
\hline
\end{tabular}




\section{DISTRIBUTION}

Number of Copies

OFFSITE

3

Central Washington University

Department of Psychology

Ellensburg, WA 98926

J. E. Eubanks, PhD

ONSITE

1

U.S. Department of Energy, Richland Operations office

DOE-RL Public Reading Room Al-65

22

Westinghouse Hanford Company

J. A. Ard

SO-05

C. L. Caldwell (3)

G6-71

A. Kowalski

K. A. Lansing

B. G. Lauzon

SO-05

N1-79

J. E. Lindsey (5)

R1-08

SO-05

E. L. Mantooth

R. M. Rogers

C. P. Seilhymer (2)

B2-66

SO-02

V. R. Treadway

G6-71

C. B. Watson

G6-73

Central Files

G6-71

Document Processing and Distribution (2)

L8-04

Information Release Administration

L8- 15

R1-08 

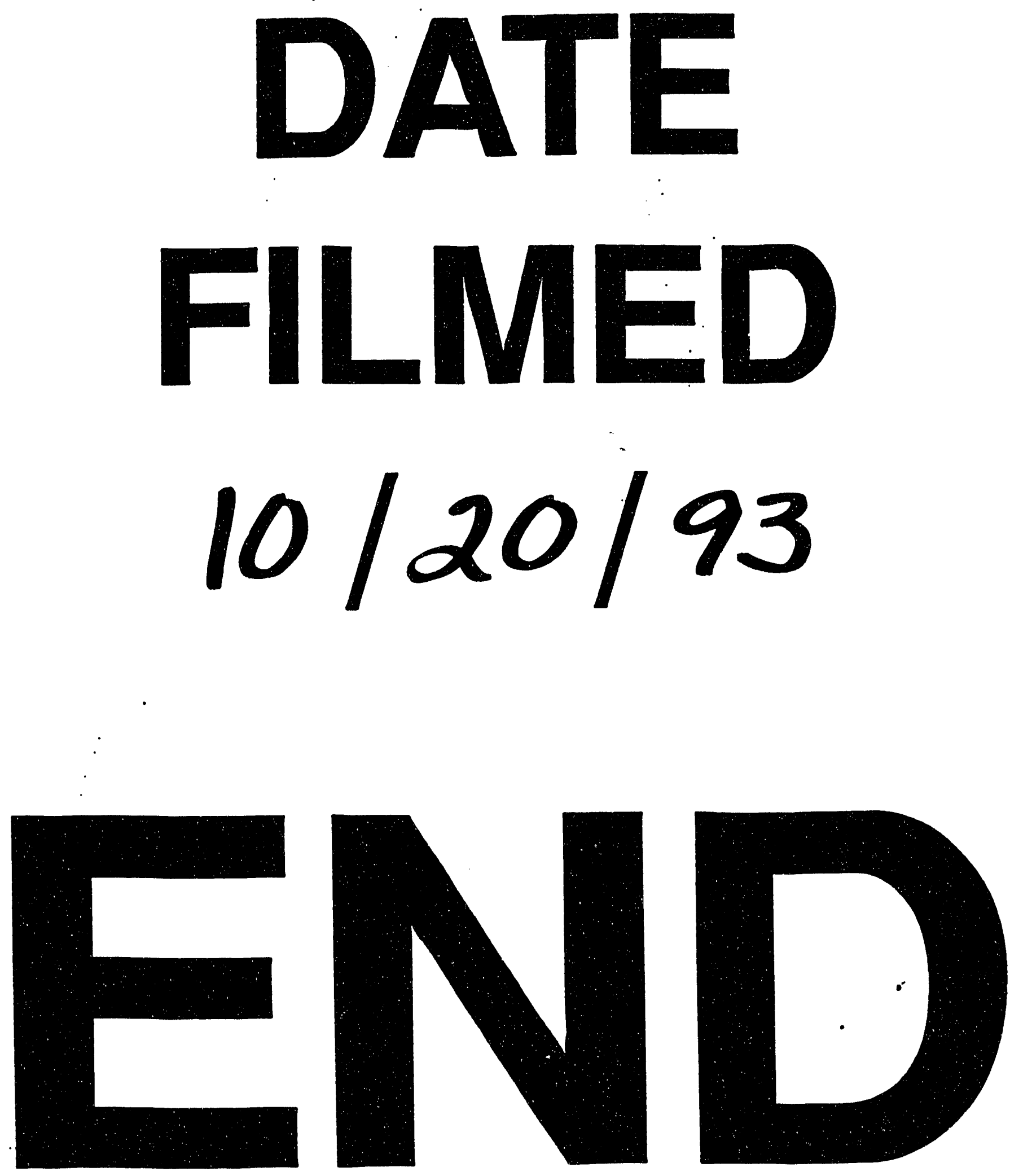
